\title{
Analysis of the functional capacity of elderly residents of communities with a rapid population aging rate
}

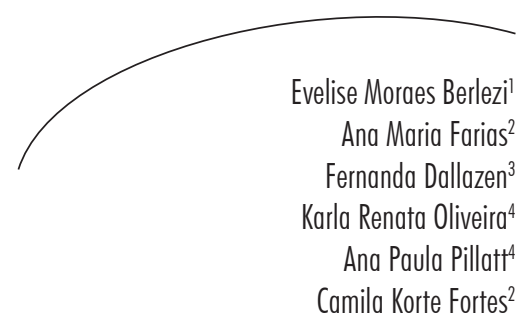

\section{Abstract}

Introduction: The elderly population has risen sharply in Brazil, increasing the need for a health policy focused on health promotion and disease prevention. Attention should also be focused on functional capacity because of the personal and family suffering caused by dependency, as well as the increased demand placed on public services. Objective: To check the health and functional capacity of elderly residents in a small town with a high population aging rate. Methods: A cross-sectional, analytical and non-probabilistic study was performed of 528 elderly persons aged $\geq 60$ years, of both genders, who were evaluated in their home environment. The variables of interest were general health and functional capacity, assessed by the adapted Katz and Lawton and Brody scales. Data analysis was carried out using descriptive and analytical statistical tools. To assess the association between variables the chi-squared test was used, accepting the hypothesis of dependency of variables with $p=0.05$. Results: The mean age was $72.24 \pm 9.33$ years. Functional capacity assessment identified that most of the elderly persons carried out activities of daily living (ADLs) and instrumental activities of daily living (IADL) independently; with percentages of $90 \%$ and $83.7 \%$, respectively. A statistically significant association was observed $(p=0.001)$ between reports of falls and functional capacity levels. Conclusion: The results show that the elderly of this municipality are mostly independent in performing their daily tasks, representing successful aging.

\footnotetext{
Universidade Regional do Noroeste do Estado do Rio Grande do Sul - UNIJUI, Departamento de Ciências da Vida. Programa de Pós-Graduação Stricto Sensu em Atenção Integral à Saúde da UNIJUI; e do Programa de Pós-Graduação Stricto Sensu em Gerontologia da Universidade Federal de Santa Maria - UFSM. Ijuí, RS, Brasil.

2 Universidade Regional do Noroeste do Estado do Rio Grande do Sul - UNIJUI, Departamento de Ciências da Vida. Curso de Fisioterapia. Ijuí, RS, Brasil.

3 Universidade Federal de Santa Maria - UFSM, Programa de Pós-Graduação Stricto Sensu em Gerontologia, Grupo de Pesquisa em Envelhecimento Humano - GERON. Santa Maria, RS, Brasil.

4 Universidade Regional do Noroeste do Estado do Rio Grande do Sul - UNIJUI, Departamento de Ciências da Vida. Ijuí, RS, Brasil.
}

Correspondence

Evelise Moraes Berlezi

E-mail: evelise@unijui.edu.br
Key words: Health profile. Elderly persons. Demographic aging. Public health. Cross-sectional studies. 


\section{INTRODUCTION}

The elderly population has risen sharply in Brazil. Since the 1940s, the highest rates of population growth have been associated with the elderly. Between 1980 and 2005, the growth of the elderly population reached $126.3 \%$, whereas overall population growth was $55.3 \% .{ }^{1}$ According to the Instituto Brasileiro de Geografia e Estatística (Brazilian Institute of Geography and Statistics) (IBGE), ${ }^{2}$ in 2010, the proportion of elderly individuals among the Brazilian population was $10.8 \%$, with the highest proportions recorded in the south of the country $(12.0 \%)$. The southern state of Rio Grande do Sul had the highest growth rate $(13.6 \%)$. Statistical projections for 2050 indicate that Brazil will have the sixth largest elderly population in the world: more than 32 million elderly individuals $(16 \%$ of the total population of the country). ${ }^{3}$

Another important indicator linked to the phenomenon of an aging population is life expectancy at birth. This indicator has also increased in recent years. In 2000, life expectancy at birth was 69.8 years, whereas in 2012, this value had risen to 74.5 years. ${ }^{4}$

However, analysis of these indicators should involve looking beyond the numbers, since the factors that favor the aging of the Brazilian population differ from those found in other countries. This is partly due to the social, economic, cultural and environmental heterogeneity that characterizes Brazil. While on one hand, this increased life expectancy is to be celebrated, on the other, it creates demands that society will need to face in order to ensure that an increase in life expectancy represents a genuine improvement.

Veras ${ }^{5}$ stated that society seeks to prolong life, but quality of life must be maintained in the additional years of life so that this increase in life expectancy can be considered an improvement rather than a problem. This statement is centered on the idea that population aging should be sustained by a health policy that is strongly focused on health promotion and the prevention of illnesses, rather than curative programs that are linked to the aging of the population.

According to Küchemann, ${ }^{1}$ an increase in life expectancy reflects cultural changes, technological advances in the health sector and improvements in living conditions. However, an increase in life expectancy leads to a greater prevalence of chronic and degenerative illnesses, which consequently cause a gradual loss in functional capacity.

Functional capacity means the ability of an individual to maintain the physical and mental functions required to preserve their independence. Functional capacity is one of the most studied dimensions in gerontology, due to the suffering of the individual and their family members. The latter suffer as a result of the dependence of the elderly individual and the increased demand for medical and social services. Among the elderly Brazilian population, the prevalence of incapacity related to activities of daily living (ADLs) was $6.5 \%$ in 1998, 6.4\% in 2003 and $6.9 \%$ in $2008 .{ }^{6}$ This data suggests that the advances in health care services for the elderly, particularly in basic healthcare, have not been reflected in the maintenance of the functional capacity of elderly individuals. In other words, the actions implemented may be reducing hospitalizations, which improves the perception of health conditions, but there are no preventive actions focused on the maintenance and restoration of functional capacity.

Considering the socio-demographic differences found in Brazil, the relevance of the present study lies in the lack of epidemiological data for elderly populations living in small municipalities where many people reside in rural areas. In general, studies of the elderly Brazilian population are conducted in large urban centers.

Thus, the present study aimed to identify differences in the aging conditions of populations that reside far from these urban centers. In addition, this research is important as it provides data referring to the health conditions of these elderly individuals. This data, together with diagnoses, 
favors the proposal of promotion, prevention and geriatric rehabilitation measures that aim to prevent the development of functional capacity or restore this capacity when it has been impaired.

The aim of the present study was to ascertain the health conditions and functional capacity of elderly individuals living in a small municipality with a high rate of population aging.

\section{METHOD}

A cross-sectional, analytical and observational study of elderly residents was performed in the municipality of Independência, in the state of Rio Grande do Sul (Brazil). The data was collected between August and October 2009.
This small municipality is located in the northeast of the Brazilian state of Rio Grande do Sul. The main economic activity in the municipality is agriculture. According to data from the Instituto Brasileiro de Geografia e Estatística (Brazilian Institute of Geography and Statistics) (IBGE), the total population of the municipality was 6618 inhabitants in 2010 (3293 men and 3325 women). The municipality contained 1233 elderly individuals (572 men and 661 women). Thus, elderly individuals represented $18.6 \%$ of the population of the municipality. Notably, the rate of population aging (approximately 10\%) was higher than that of the state of Rio Grande do Sul. Table 1 displays the distribution of the elderly individuals according to age group, gender, study population and representativity.

Table 1. Distribution of elderly individuals in the municipality of Independência, Rio Grande do Sul, according to age, gender, sample size and representativity, 2010.

\begin{tabular}{lccccc}
\hline \multicolumn{1}{c}{ Age group } & Men & Women & Total & Population of the study & Representativity \\
\hline 60 to 64 years & 185 & 184 & 369 & 131 & $35.5 \%$ \\
65 to 69 years & 144 & 136 & 280 & 104 & $37.1 \%$ \\
70 to 74 years & 99 & 129 & 228 & 106 & $46.4 \%$ \\
75 to 79 years & 79 & 100 & 179 & 74 & $41.3 \%$ \\
$\geq 80$ years & 65 & 112 & 177 & 113 & $63.8 \%$ \\
\hline Total & 572 & 661 & 1233 & 528 & $42.8 \%$ \\
\hline
\end{tabular}

In total, 528 elderly individuals (60 years or more) of both genders were visited in their homes. This sample represented $42.8 \%$ of the elderly population in the municipality. The participants were selected based on convenience.

The entire population (100\%) of the municipality of Independência is covered by the Estratégia da Saúde da Família (Family Health Strategy), which involves two health teams. Each team deals with one territory, which is divided into eight micro-regions. The research was helped by the Municipal Council of Independência through the Municipal Health Secretary, which consented to the participation of community health workers
$(\mathrm{CHW})$ in the collection of data and ensured that adequate conditions were available for training activities and data collection. In total, $16 \mathrm{CHWs}$ participated in the data collection stage: eight from each health team; and one from each micro-region.

The training involved discussions concerning population aging, healthcare policies for the elderly, functional capacity, assessment protocols and the application methods used for these protocols. In order to certify the observers (CHW) and prevent system errors, 16 elderly individuals were selected (one per micro-region) for the application of the research instruments. These 16 elderly individuals were excluded from the study population. 
An interview that addressed the sociodemographic data (age, gender and education) and general health conditions (presence of comorbidities and illnesses, use of drugs and history of falls) was conducted to obtain the data required.

The Katz scale for independence in $\mathrm{ADLs}^{7}$ and the adapted Lawton and Brody scale ${ }^{8}$ were used to assess the functional capacity of the elderly individuals.

The Katz scale is used to measure the ability of an individual to perform their daily activities independently, thereby determining the rehabilitation interventions required. The Katz scale focuses on the performance of the elderly individual and the degree of assistance they require in six basic categories: bathing; dressing; going to the bathroom; moving around; continence and eating. Each task receives a score of between zero (independent) and three (complete dependence). A score of one indicates that the elderly individual needs an object to perform the task, while a score of two indicates that they need human help to perform the task.

The Lawton and Brody scale was proposed to assess instrumental activities of daily living (IADLs), which are considered more complex than basic ADLs. Independence while performing these activities is directly correlated with the capacity of the individual to experience independent community life. The Lawton scale analyzes the capacity of the elderly individual to adapt to their environment and includes a wide range of activities, including using the telephone, going shopping, preparing meals, cleaning the house, washing clothes, gardening, using modes of transport, climbing stairs, taking medication and financial planning. The adapted version of the scale was used, with a maximum score of 21 points and the following possibilities for each item: performs the activities independently ( 3 points); needs help with some part of the task (2 points); and cannot perform the activity (1 point). ${ }^{10}$
The Statistical Package for Social Sciences (SPSS) software was used to process the data. Descriptive statistics used central tendency and dispersion measurements to analyze the quantitative variables and the absolute and relative frequencies for the qualitative variables. The chi-squared test of associations for categorical variables was used in the statistical analysis, in which the hypothesis of dependence for the variables was set at $p \leq 0.05$.

The present study received approval from the Ethics Committee of Unijuí under protocol number 241/2009. All of the elderly individuals who agreed to participate signed a free and informed consent form.

\section{RESULTS}

In total, 528 elderly individuals, with a mean age of $72.24 \pm 9.33$ years, participated in the present study (minimum age of 60 years and maximum age of 99 years). The vast majority (95\%) of the participants were aged between 71.44 and 73.04 years. When comparing the mean age in accordance with gender, no significant differences were found between the groups $(p=0.90)$. The study population contained more women than men (51.7\%).

Each elderly participant exhibited a mean of $3.25 \pm 2.39$ comorbidities and illnesses, while the confidence interval showed that $95 \%$ of the elderly individuals exhibited between 3.05 and 3.46 such conditions. Notably, 13.4\% (71) did not exhibit comorbidities or illnesses, while 44.4\% (234) had between one and three, $31.7 \%$ (168) had between four and six and 10.5\% (55) had more than six.

Concerning the general health conditions of the sample, the most common comorbidities and illnesses were: systemic arterial hypertension (SAH) (53.9\%); dizziness (41.9\%), loss of sight $(39.4 \%)$ and loss of memory (38.4\%). All other comorbidities and illnesses were less than $30 \%$.

In total, 371 of the 528 elderly participants used some form of medication, which is equal to 
$70.4 \%$ of the study population. Analysis of the use of medication according to gender confirmed that $78.3 \%$ (213) of the women and $62 \%$ (158) of the men took some form of drug. The chi-squared test confirmed an association between gender and the use of medication (0.000).

Analysis of the quantity of falls suffered in the year prior to the interview confirmed that $19.9 \%$ (105) of the participants had suffered at least one fall in the time period in question. The history of falls was higher for women than for men, with results of $25.4 \%$ (69) and $14.1 \%$ (36), respectively.

The Katz scale for ADLs confirmed the following results: 94.1\% (497) of the elderly participants were classified as independent for "bathing"; 94.7\% (500) "were able to dress themselves without help"; 97\% (512) were able to perform activities related to "personal hygiene"; $97 \%$ (512) were "able to move around without the help of others"; $85 \%$ (449) were "continent"; and 96.4\% (509) could feed themselves without help from others.

Analysis of the distribution of frequencies of the levels of functional capacity for bathing, dressing, personal hygiene, getting around, continence and eating confirmed that more than $90 \%$ of the men and women in the study performed their ADLs independently, whereas less than $4 \%$ required some form of assistance.

According to the assessment of IADLs in accordance with the categorization of the Lawton scale, $83.7 \%$ (442) of the participants were independent, $13.8 \%$ (73) were semi-dependent and $2.5 \%$ (13) were dependent. Analysis by gender showed that the majority of the men and women were classified as independent in relation to IADLs ( $85.1 \%$ and $82.4 \%$, respectively).

The assessment of IADLs for telephone use confirmed that $62.9 \%$ (332) "can receive and make telephone calls without any assistance". As for getting around, 67.8\% (358) "travel alone". Concerning the ability to go shopping, $75.4 \%$ (398) of the interviewees "go shopping if transport is provided". With regards to the preparation of meals, $75.9 \%$ (401) "are able to plan and prepare complete meals".

Concerning domestic tasks, 46.4\% (245) could "perform difficult tasks". As for the ability to take care of their own medication, $84.3 \%$ (445) "take their medication without assistance". In relation to using their money, 63.6\% (336) of the interviewees "pay their own bills and/or use checks without assistance".

In order to assess the association between a history of falls and the level of functional capacity for IADLs, dependent/semi-dependent and independent groups were established. The results obtained confirmed that 28 of the 105 elderly individuals who had suffered falls $(26.7 \%)$ were dependent or required assistance to perform their IADLs, while $73.3 \%$ (77) were independent. A statistically significant association $(p=0.001)$ was found between falls and functional capacity related to the performance of IADLs.

\section{DISCUSSION}

The mean age of the participants in the present study was $72.24 \pm 9.33$ years. The standard deviation value confirmed that there was very little variability between the ages of the elderly individuals, as confirmed by the confidence interval of 95\% (71.44 and 73.04 years). This investigation contained more women than men. However, when comparing this result to others found in literature, there was a greater percentage difference between genders: Barbosa et. al. ${ }^{11}$ and Santos and Griep ${ }^{12}$ reported a greater prevalence of women, with $63.3 \%$ and $71 \%$, respectively.

The issue of gender and old age has been widely discussed, particularly due to the fact that women tend to live longer than men. This phenomenon was addressed in the above mentioned studies and has been labelled the feminization of the elderly. Several other studies ${ }^{13,14}$ have addressed this issue, which deserves special attention given that we cannot interpret the fact that women live longer as 
meaning that they maintain a satisfactory quality of life and desirable health conditions. Until now at least, studies have shown that these variables are not associated in such a positive light.

$\mathrm{Neri}^{13}$ stated that gender is a more significant risk factor than age when analyzing health, physical functionality and perceived health, since elderly women are more frail (and know that they are more frail) than elderly men. The authors concluded that when the effects of physical frailty are added to the effects of certain socio-demographic variables, such as living alone, having less education, caring for others or requiring care, the quality of life of elderly women tends to decline.

When gender issues are associated with age and dependence, studies have reported that the social involvement of women is more negatively affected by advancing age due to their greater longevity and the increased risk of dependence. Elderly women tend to experience more isolation and loneliness. They have a more negative image of themselves, old age and other elderly individuals than elderly men. ${ }^{15}$

The phenomenon of the feminization of the elderly is seen as a medical and social problem. Conversely, the prevalence of chronic illnesses is higher among elderly men, although this is likely change in future generations, given that contemporary women are exposed to the same type of risk factors as men today. ${ }^{13}$

Concerning gender and functional capacity, a study by Virtuoso and Guerra ${ }^{16}$ reported that several factors can decrease the quality of life of elderly women, including older age groups, when accompanied by functional limitations. Functional conditions affect the performance of ADLs when associated with morbidities. ${ }^{17}$

Based on the functional capacity results for the participants of the present study, more than $90 \%$ of the elderly individuals in the municipality had preserved their functional capacity for ADLs. This result could be explained by the characteristics of this population (elderly individuals with an active lifestyle). The women performed daily household tasks and looked after the outside of the house (garden, yard etc.), while also caring for animals and collecting milk. The men were involved in tasks that demanded physical strength. In addition, these individuals tend to travel short or medium distances on foot or on a bicycle, as is common in rural areas where agriculture is the most significant economic activity (such as the municipality of Independencia).

Functional capacity involves much more than performing daily tasks and consists of maintaining the physical and mental skills required to have an independent life. Thus, functional capacity means complete autonomy so that an individual can do all the things they want, and is related to physical, intellectual, emotional and cognitive aspects. ${ }^{18}$

In theory, age associated with disabling diseases would increase the risk of developing functional dependence. Conversely, an environment that stimulates an active lifestyle reduces the impact of illnesses on functional capacity.

Studies such as those by Rosa et al. (2003) and Kattainen et al. (2004) demonstrated significant associations between chronic illnesses and the functional incapacity of elderly individuals. ${ }^{19,20}$ When multiple chronic conditions exist, disabilities can develop as a result of a single illness or a combination of illnesses, causing the elderly individual to become progressively more fragile and dependent for ADLs. ${ }^{21}$

Systemic arterial hypertension ( $\mathrm{SAH}$ ) was the most common chronic illness identified among the participants of the present study. This finding corroborates the results of Focchesatto, Rockett and Perry, ${ }^{22}$ who found SAH in $64.3 \%$ of the elderly individuals studied. During the process of senescence, the arteries suffer multiple alterations that affect the predisposition by increasing blood pressure. Over time, this increase can have deleterious effects on vital organs such as the heart and brain.

SAH is a multifactorial condition and one of the factors that affects physical activity. It can also affect functional capacity. According to HAJAR 
et al., ${ }^{23}$ elderly individuals with SAH are at an increased risk of developing functional incapacity for functions related to normal blood pressure. The same authors also showed that individuals with hypertension, particularly uncontrolled arterial hypertension, are significantly more likely to develop a disability, irrespective of other risk factors and comorbidities.

Physical inactivity in old age may be correlated to the health conditions of the individual or their failure to adopt an active lifestyle. In the present study, the high prevalence of SAH could be the result of senescence or cardiovascular illnesses, since the study population was characterized as active. ${ }^{24}$

When studying elderly populations, functional incapacity is one of the most common indicators used as a health predictor. It is particularly useful when assessing social requirements and the use of health services. This indicator has been used to assess the performance of elderly individuals during basic and instrumental activities of daily living, which are considered determinants of personal independence and the capacity of an individual to socialize, interact and work. ${ }^{25}$

When the functional capacity of an elderly individual is impaired, there are significant implications for their family members, the community, the health system and their life. Incapacity leads to greater vulnerability and dependence in old age, thereby contributing to a decrease in the wellbeing and quality of life of elderly individuals. ${ }^{26}$

Leite et al. ${ }^{27}$ assessed the functional capacity and cognitive level of elderly individuals living in a municipality of Rio Grande do Sul, Brazil and found that most of the participants $(93.8 \%)$ were independent, both in terms of performing IADLs and ADLs. These results are similar to those found in the present study. Fiedler and Peres also studied elderly individuals in the south of Brazil and found that $37.1 \%$ of the sample exhibited limitations in relation to their functional capacity. ${ }^{28}$

Barbosa $\mathrm{et} \mathrm{al.}{ }^{29}$ studied 286 elderly individual aged between 60 and 103 years (mean age of 71.2 years) and found that $6.6 \%$ of the participants were dependent for up to three basic activities and 5.6\% were dependent for more than three activities. The elderly individuals mainly required help with micturition (9.4\%), dressing (7.6\%) and bathing $(6.6 \%)$. For IADLs, we considered individuals who were only dependent in relation to IADLs and those who were dependent for both IADLs and basic ADLs. The greatest dependence was recorded for travelling longer distances alone $(24.1 \%)$, washing and ironing clothes $(22.0 \%)$ and using the telephone $(18.9 \%)$.

Fialho et al. ${ }^{30}$ studied 1624 individuals aged between 60 and 97 years and reported the following results: $64.2 \%$ of the sample were independent for all IADLs and basic ADLs; $19.6 \%$ had some degree of difficulty with at least one IADL; and $16.2 \%$ had some degree of difficulty with one or more basic ADLs. All of the individuals who exhibited some degree of difficulty with a basic ADL also had some degree of difficulty with at least one IADL.

ADLs and IADLs are activities that present a certain degree of difficulty for elderly individuals, especially those who have a health issue. However, it is clear that IADLs are more complex than basic ADLs, mainly due to the social involvement element. Thus, many elderly individuals are capable of performing all of the tasks in their home but feel useless when they must perform an activity that involves social contact that is not part of their daily lives.

As chronological age increases, people tend to become less active and their functional capacity is reduced. Chronic illnesses are very common among individuals aged 75 years or more, which contributes to the degenerative process, thereby reducing the independence of elderly individuals. Studies have shown that approximately $25 \%$ of all elderly individuals worldwide depend on the help of others to perform ADLs. ${ }^{31}$

According to Costa, Porto and Soares, ${ }^{32}$ between 30 and $50 \%$ of very old individuals (85 years or more) are unable to perform at least five ADLs and require full-time care. This condition 
worsens when illnesses are involved, particularly if they are neurological in nature.

Wellbeing in old age, or health in a broader sense, is the result of a balance between the different dimensions of the functional capacity of the elderly individual. These dimensions address biological, social, emotional and spiritual factors equally. ${ }^{33}$

Estimates for 2020 predict an increase of between $84 \%$ and $167 \%$ in the number of elderly individuals with moderate or severe incapacity. ${ }^{34}$ This highlights the importance of proposing health programs that address all levels of healthcare for the elderly, particularly at primary and secondary levels, at which point worsening health conditions can be detected at the earliest stages, thereby preventing the development of disabilities that lead to dependence..$^{35}$

The aim of active aging policies is to increase healthy life expectancy while ensuring quality of life, even for individuals who are frail, physically disabled or require care. ${ }^{36}$ However, the environment in which the individual lives can stimulate or inhibit the adoption of an active lifestyle. When considering this concept in terms of the present study, it is possible to infer that the environment in which the elderly individuals live (the municipality of Independência) stimulates an active lifestyle.

Analysis of the data obtained from the present study identified a number of limitations, although they do not affect the validity of the results presented. Further studies with other populations could expand our understanding of the phenomenon in question. The limitations of this research include: frailty indicators among the elderly individuals were not identified; and frailty was not assessed by considering unintentional weight loss in the previous year, handgrip strength and gait speed, as described by Fried. ${ }^{37}$ The phenotype of frailty in the elderly population would help our understanding of dependence or semi-dependence situations related to the performance of ADLs, while also enabling the health service of the municipality to deal with demand in a hierarchical manner, subsidize the planning of health teams and define promotion, prevention and intervention programs (individually or collectively) in order to prevent, maintain or restore the functional capacity of the elderly and preserve their independence, thereby ensuring a dignified old age and a satisfactory quality of life.

\section{CONCLUSION}

The results of the present study showed that elderly individuals from the municipality of Independência in the state of Rio Grande do Sul exhibited no functional limitations for instrumental and basic activities of daily living. However, they exhibited a high prevalence of illnesses and comorbidities, which could affect their functional capacity over time and lead to dependence for ADLs.

In order to maintain the functional capacity of the elderly population throughout the longer lives they are living today, it is important to implement basic healthcare strategies and programs that stimulate the active aging of these populations and detect conditions that can lead to disabilities as early as possible. Furthermore, due to the complexity of healthcare for the elderly, care networks that ensure full-time, continuous and resolute care are required for the health of these populations. 


\section{REFERENCES}

1. Küchemann BA. Envelhecimento populacional, cuidado e cidadania: velhos dilemas e novos desafios. Soc Estado 2012;27(1):165-80.

2. Rede Interagencial de Informações para a Saúde [Internet]. Proporção de idosos na população. Brasília, DF: Ministério da Saúde; 2015 [acesso em 10 julho de 2015]. Disponível em: http://tabnet.datasus. gov.br/cgi/tabcgi.exe?idb2012/a14.def

3. Aires M, Paskulin LMG, Morais EP. Capacidade funcional de idosos mais velhos: estudo comparativo em três regiões do Rio Grande do Sul. Rev Latinoam Enferm 2010;18(1):11-7.

4. Instituto Brasileiro de Geografia e Estatística [Internet]. Gerência de estudos e análises da dinâmica demográfica- 2000 a 2012: projeção da população do Brasil e das unidades da federação, por sexo e idade para o período 2000-2030. Rio de Janeiro: IBGE; 2015 [acesso em 15 mar 2015]. Disponível em: http:// www.ibge.gov.br/home/estatistica/populacao/ projecao_da_populacao/2013/default.shtm

5. Veras R. Envelhecimento populacional contemporâneo: demandas, desafios e inovações. Rev Saúde Pública 2009;43(3):548-54.

6. Lima-Costa MF, Matos DL, Camargos VP, Macinko J. Tendências em dez anos das condições de saúde de idosos brasileiros: evidências da Pesquisa Nacional por Amostra de Domicílios (1998, 2003, 2008). Ciênc Saúde Coletiva 2011 [acesso em 03 ago 2015];16(9):3689-96.

7. Katz SMD, Amasa B, Ford MD, Roland W, Moskowitz MD, Beverly A, et al. Studies of illness in the aged. The index of ADL: a standardized measure of biological and psychosocial function. JAMA 1963;185(12):914-19.

8. Lawton MP, Brody EM. Assessment of older people: self-maintaining and instrumental activities of daily living. Gerontologist 1969;9(3):179-86.

9. Brasil. Ministério da Saúde. Envelhecimento e saúde da pessoa idosa. Brasília, DF: Ministério da Saúde; 2006. (Série A. Normas e Manuais Técnicos); (Cadernos de Atenção Básica, no 19).

10. Santos RL, Virtuoso JS Júnior. Confiabilidade da versão brasileira da escala de atividades instrumentais da vida diária. Rev Bras Promoç Saúde 2008;21(4):290-6.

11. Barbosa BR, Almeida JM, Barbosa MR, RossiBarbosa LA. Avaliação da capacidade funcional dos idosos e fatores associados à incapacidade. Ciênc Saúde Coletiva 2014;19(8):3317-25.
12. Santos MIPO, Griep RH. Capacidade funcional de idosos atendidos em um programa do SUS em Belém (PA). Ciênc Saúde Coletiva 2013;18(3):753-61.

13. Neri AL. Envelhecimento e qualidade de vida na mulher. In: Anais do $2^{\circ}$ Congresso Paulista de Geriatria e Gerontologia; 2001 Campinas. São Paulo:Universidade Federal de Campinas; 2001. p.6-13.

14. Almeida AV, Mafra SCT, Da Silva EP, Kanso S. A Feminização da Velhice: em foco as características socioeconômicas, pessoais e familiares das idosas e o risco social. Textos \& Contextos (Porto Alegre) 2015;14(1):115-31.

15. Kimmel D. Aduthood and aging. New York: John Wiley \& Sons; 1994.

16. Virtuoso JS Junior, Guerra RO. Fatores associados às limitações funcionais em idosas de baixa renda. Rev Assoc Med Bras 2008;54(5):430-35.

17. Pedrazzi EC, Rodrigues RAP, Schiaveto FV. Morbidade referida e capacidade funcional de idosos. Ciênc Saúde Coletiva 2007;6(4):407-13.

18. Gordilho AJ, Sérgio J, Silvestre J, Ramos LR, Freire MPA, Espindola N, et al. Desafios a serem enfrentados no terceiro milênio pelo setor da saúde na atenção integral ao idoso: envelhecimento humano. Rio de Janeiro: UnATI/UERJ; 2000.

19. Rosa TEC, Benicio MHD, Latorre MRDO, Ramos LR. Fatores determinantes da capacidade funcional entre idosos. Rev Saúde Pública 2003;37(1):40-8.

20. Kattainen A, Koskinen S, Reunanen A, Martelin T, Knekt P, Aromaa A. Impact of cardiovascular diseases on activity limitations and need for help among older persons. J Clin Epidemiol 2004;57(1):82- 8.

21. Guccione AA, Felson DT, Anderson JJ, Anthony JM, Zhang Y, Wilson PW, et al. The effects of specific medical conditions on the functional limitations of elders in the Framingham study. Am J Public Health 1994;84:351-8.

22. Focchesatto A, Rockett FC, Perry IDS. Fatores de risco e proteção para o desenvolvimento de doenças crônicas em população idosa rural do Rio Grande do Sul. Rev Bras Geriatr Gerontol 2015;18(4):779-95.

23. Hajjar I, Lackland D, Cupples LA, Lipsitz LA. The association between concurrent and remote blood pressure and disability in older adults. Hypertension 2008;150(6):1026-32.

24. Scher LML, Nobre F, Lima NKC. O papel do exercício físico na pressão arterial em idosos. Rev Bras Hipertens 2008;15(4):228-3. 
25. Arias MED, Mendoza RNM, Ortiz GG, Velazquez BIE, Meda LRM, Cueva CJ. Physical function and associated factors in community dwelling elderly people in Jalisco, Mexico. Arch Gerontol Geriatr 2012;54(3):271-8.

26. Alves LC, Leimann BCQ, Vasconcelos MEL, Carvalho MS, Vasconcelos AGG, Fonseca TCO, et al. A influência das doenças crônicas na capacidade funcional dos idosos do Município de São Paulo, Brasil. Cad Saúde Pública 2007;23(8):1924-30.

27. Leite MT, Castioni D, Kirchner RM, Hildebrandt LM. Capacidade funcional e nível cognitivo de idosos residentes em uma comunidade do sul do Brasil. Enferm glob 2015;14(37):1-11.

28. Fiedler MM, Peres KG. Capacidade funcional e fatores associados em idosos do Sul do Brasil: um estudo de base populacional. Cad Saúde Pública 2008;24(2):409-15.

29. Barbosa BR, De Almeida JM, Barbosa MR, RossiBarbosa LAR. Avaliação da capacidade funcional dos idosos e fatores associados à incapacidade. Ciênc Saúde Coletiva 2014;19(8):3317-25.

30. Fialho CB, Lima-Costa MF, Giacomin, KC, De Loyola Filho AI. Capacidade funcional e uso de serviços de saúde por idosos da Região Metropolitana de Belo Horizonte, Minas Gerais, Brasil: um estudo de base populacional. Cad Saúde Pública 2014;30(3):599-610.
31. Guimarães ACA, Mazo GZ, Simas JPN, Salin MS, Schwertner DS, Soares D, et al. Idosos praticantes de atividade física: tendência a estado depressivo e capacidade funcional. Rev Efdeportes 2006;10:(94):1-2.

32. Costa EFA, Porto CC, Soares AT. Envelhecimento populacional brasileiro e o aprendizado de geriatria e gerontologia. Rev UFG 2003;5(2):1-12.

33. Lima MF, Barreto SM, Giatti L. Condições de saúde, capacidade funcional, uso de serviços de saúde e gastos com medicamentos da população idosa brasileira: um estudo descritivo baseado na Pesquisa Nacional por Amostra de Domicílios. Cad Saúde Pública 2003;19(3):735-43.

34. Matsudo SM, Matsudo VKR, Barros TL Neto. Impacto do envelhecimento nas variáveis antropométricas, neuromotoras e metabólicas da aptidão física. Rev Bras Ciênc Mov 2000;8(4):21-32.

35. Camarano AA. Envelhecimento da população brasileira. In: Freitas EV, Py L, organizadores. Tratado de Geriatria e Gerontologia. 1a ed. Rio de Janeiro: Guanabara Koogan; 2002. p.58-71.

36. Organização Mundial da Saúde. Envelhecimento ativo: uma política de saúde. Brasília. DF: Organização Pan-Americana da Saúde; 2005.

37. Fried LP, Tangen CM, Walston J, Newman AB, Hirsch C, Gottdiener J, et al. Frailty in older adults: evidence for a phenotype. J Gerontol Ser A Biol Sci Med Sci 2001;56(3):146-56. 